\title{
Solid state NMR studies of fire-induced changes in the structure of humic substances
}

\author{
G. Almendros ${ }^{a}$, F.J. González-Vila ${ }^{b}$, F. Martín ${ }^{b}$, R. Fründ ${ }^{c}$ and \\ H.-D. Lüdemann ${ }^{c}$ \\ ${ }^{a}$ Centro de Ciencias Medioambientales, (C.S.I.C.). Serrano 115 dpdo., E-L 28006-Madrid, \\ Spain \\ ${ }^{b}$ Instituto de Recursos Naturales y Agrobiología, (C.S.I.C.). P.O. Box 1052, E-L \\ 41080-Seville, Spain \\ 'Institut für Biophysik und physikalische Biochemie, P.O. Box 397, D-8400 Regensburg, \\ Germany
}

\section{ABSTRACT}

Several structural changes were recognized by CPMAS ${ }^{13} \mathrm{C}-\mathrm{NMR}$ and resolutionenhanced IR spectroscopy after humic acids (HA) and fulvic acids (FA) were subjected to laboratory heating at $350^{\circ} \mathrm{C}$. The NMR results suggested that the HA underwent decarboxylation, selective transformation of aliphatic material, and increase in the number of aromatic carbons when subjected to heating for $120 \mathrm{~s}$, whereas after subsequent heating no predominant aromatic neoformations were observed, and the elimination of alkyl structures occurred preferentially at this stage. The infrared spectroscopy revealed a well-defined lignin pattern in the original HA, that tended to disappear with heating. The results obtained in the laboratory experiments agreed with several of the differences found between the NMR patterns of the humic substances from the unburnt soil area and from that affected by forest fire. It is suggested that the changes observed play important roles in the colloidal properties and the water-repellency observed in the heated humic substances and in the post-fire soil area.

Key words: humic acids; fulvic acids; NMR; fire; heating effects

\section{INTRODUCTION}

In spite of the frequent occurrence of forest fires in Mediterranean areas, their effects on the chemistry of the humic substances has only been discussed in a small number of studies. In contrast with the more or less complete destruction of the vegetation cover, the soil humus often reflects changes of chemical composition rather than severe losses in the total organic carbon [1-5].

Most information concerning the fire-induced effects on soils has been obtained from laboratory simulations. In fact, the simultaneous occurrence of 
different processes during forest fires (selective destruction of humus fractions, chemical changes in the soil organic matter, and external inputs of charcoal and charred lignocellulose) makes it extremely difficult to explain the origin of humus transformations in burned areas. Changes in the soil water-repellency, in the total amounts and stability of the different $\mathrm{N}$-forms and exchange cations, and in the degradation patterns of humic substances have been reported from laboratory experiments [6-9].

A realistic evaluation of the amounts of the different structural units in the humic substances can be achieved by the use of ${ }^{13} \mathrm{C}$-NMR spectroscopy under quantitative acquisition conditions. Such a technique has been found suitable for determining the presence of humic moieties (viz., O-alkyl structures) otherwise underestimated by oxidative degradation methods [10].

The present note reports the effects of progressive laboratory heating on the ${ }^{13} \mathrm{C}-\mathrm{NMR}$ patterns of a humic acid (HA) and a fulvic acid (FA) from a forest soil under evergreen oak. The spectra of the corresponding substances from a neighbouring site, affected by wildfire, are also presented.

\section{MATERIALS AND METHODS}

\section{Humic samples}

The characteristics of the soil studied (Dystric Xerochrept) and of its humic substances were described elsewhere [11]. Soil $\mathrm{pH}$ was $4.8 ; \% \mathrm{C}=1.4$; $\mathrm{C} / \mathrm{N}=16 ; \mathrm{CEC}=10 \mathrm{cmol}_{\mathrm{C}} / \mathrm{kg}$. The sample from the control site $(\mathrm{C})$ under Quercus rotundifolia forest was prepared by mixing five soil subsamples $\left(\mathrm{A}_{0}+\mathrm{A}_{1}\right.$ horizons $=10 \mathrm{~cm}$ depth $)$ from a $50 \mathrm{~m}^{2}$ flat area. The HA was extracted with $0.1 \mathrm{M} \mathrm{NaOH}$, precipitated with conc. $\mathrm{HCl}$, de-ashed by $0.1 \mathrm{M}$ $\mathrm{HCl}-\mathrm{HF}$ treatment followed by $37000 \times g$ centrifugation at $\mathrm{pH}=12$ and dialysed.

The FA was concentrated by using an insoluble polyvinylpyrrolidone column (Divergan-R, BASF), eluted with $0.1 \mathrm{M} \mathrm{NaOH}$ and chromatographed in an Amberlite IR-120 column to recover the $\mathrm{Na}^{+}$-free FA. The HA from this control site (HA-C) had $52 \% \mathrm{C}, 6 \% \mathrm{H}, 38 \% \mathrm{O}, 4 \% \mathrm{~N}$ whereas the fulvic acid (FA-C) had $46 \% \mathrm{C}, 3 \% \mathrm{H}, 50 \% \mathrm{O}$ and $1 \% \mathrm{~N}$. The soil area $\mathrm{B}$ was affected by a forest fire 15 months ago and was separated from the $\mathrm{C}$ area by a forest road. The corresponding humic fractions were labelled as HA-B and FA-B.

In the laboratory experiments, the $\mathrm{HA}-\mathrm{C}$ or FA-C were heated at $350^{\circ} \mathrm{C}$ in a tubular furnace [11]. The time periods (60-150 s) in which the samples were kept at the maximum temperature zone of the furnace were selected from the data reported for medium-intensity fires in Mediterranean formations [2] where temperatures may range between 400 and $100^{\circ} \mathrm{C}$ in terms of depth. 
High-resolution solid state ${ }^{13} \mathrm{C}$-NMR spectra were obtained with the CPMAS technique at $75.4 \mathrm{MHz}$ in a Bruker MSL 300 spectrometer. Magic angle spinning was performed at $4 \mathrm{kHz}$ in the commercial Bruker double bearing probes in phase stabilized zirconium oxide rotors [12]. Cross polarization and proton decoupling were used, and 2500 FID's were accumulated at a time interval of $2.5 \mathrm{~s}$.

\section{Resolution-enhanced infrared spectroscopy}

The different procedures for resolution enhancement based on mathematical treatments of spectral data yield valuable information in the case of complex polymer materials, where the broad peaks are mostly due to the overlapping of a series of neighbouring bands [13-15]. Such methods may be especially helpful for the present study, since it is well known that progressive maturation, coalification or thermal treatment lead to featureless spectral profiles of humic substances.

The method used here is based on subtracting from the raw spectrum a positive multiple of its 2 nd derivative, a procedure classically used in digital image processing [16]. The IR spectra ( $\mathrm{KBr}$ pellets with $2.0 \mathrm{mg}$ sample) were acquired in the $2000-600 \mathrm{~cm}^{-1}$ range ( 1400 data points) with a Perkin-Elmer 683 spectrophotometer and processed with the authors' program in a personal computer. The noise was reduced by 100 iterations of local smoothing by moving averages, and the factor 1500 was used to multiply the second derivative.

\section{RESULTS AND DISCUSSION}

The quantitative results from the integration of selected regions in the ${ }^{13} \mathrm{C}-\mathrm{NMR}$ spectra (Fig. 1) are shown in Table 1. The curves showed in Fig. 2 were obtained when the percentages of the different $C$ types determined by NMR were calculated in terms of the $C$ losses in laboratory conditions. In the case of the HA, the depletion of alkyl and O-alkyl materials was substantial; the amount of carboxyl C's also decreased progressively, but that of aromatic C's increased with the heating time. The latter fact could be explained from the neoformation of unsaturated and/or aromatic material during the heating of O-alkyl constituents such are sugars, a phenomenon observed during carbohydrate dehydrations leading to the formation of melanoidins [17-19].

The progressive depletion steps were studied from the difference spectra in Fig. 3 (the spectrum corresponding to the early step is paired with that of the subsequent step and their total spectral intensities are normalized; the lat- 

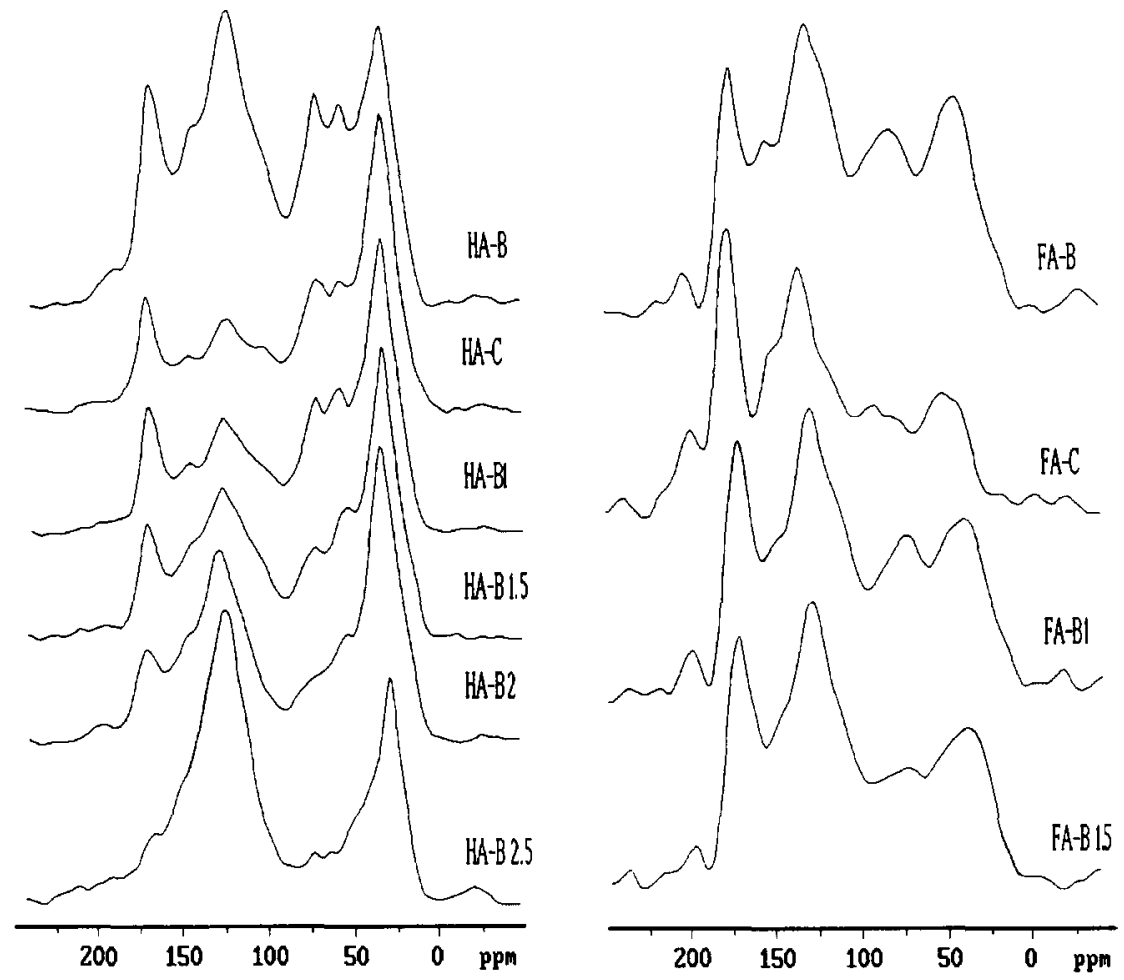

Fig. 1. CPMAS ${ }^{13} \mathrm{C}$-NMR spectra of humic acids (HA) and fulvic acids (FA) from the unburnt control area of a Dystric Xerochrept under oak forest (C), from the post-fire area (B), and of laboratory-heated humic substances (B1-B2.5).

ter spectrum is linearly scaled by a suitable factor from the total $\mathrm{C}$ loss in the corresponding time interval, and subtracted from the former). Some negative regions may be noted in such spectra, whereas only positive values should be expected if the thermal transformation were exclusively due to selective losses of humic structures. This is attributed to the abovementioned probable reorganization of humus material, as a result of heating: the negative areas would reflect the positive balance for certain types of structures (mainly alkyl and aromatic) that may come from dehydration of a portion of the $\mathrm{O}$-alkyl constituents.

Selective loss of aliphatic material during the early heating phases of the HA was observed (Fig. 3). Both the amounts of O-alkyl and carboxyl carbons decreased, whereas those in heteroaromatic structures increased, as suggested by the negative signal centred at around $152 \mathrm{ppm}$. In the intermediate phase (HA-B1.5-HA-B2) the difference spectrum resembled a typical carbohydrate with the characteristic signals centred at 103, 75 and 63 
TABLE 1

Characteristics of humic substances subjected to heating

\begin{tabular}{|c|c|c|c|c|c|c|c|c|c|}
\hline \multirow[t]{2}{*}{$\begin{array}{l}\text { Sample } \\
\text { reference }\end{array}$} & \multirow{2}{*}{$\begin{array}{l}\text { Heating time } \\
\text { at } 350^{\circ} \mathrm{C} \\
\text { (seconds) }\end{array}$} & \multirow[t]{2}{*}{$\begin{array}{l}\% \text { wt } \\
\text { loss }\end{array}$} & \multicolumn{2}{|c|}{ Solubility (\%) } & \multirow[t]{2}{*}{ WDPT $^{a}$} & \multicolumn{4}{|c|}{$\begin{array}{l}\% \text { Area of the }{ }^{13} \mathrm{C}-\mathrm{NMR} \\
\text { spectral regions (ppm) }\end{array}$} \\
\hline & & & $\mathrm{pH}=1$ & $\mathrm{pH}=12$ & & $200-160$ & $160-110$ & $110-46$ & $46-0$ \\
\hline HA-B & 一 & - & 0.0 & 100.0 & 15 & 14.7 & 32.7 & 32.1 & 20.5 \\
\hline HA-C & 0 & 0.0 & 0.0 & 100.0 & 12 & 13.1 & 19.0 & 35.1 & 32.8 \\
\hline HA-B1 & 60 & 10.1 & 0.3 & 50.2 & 15 & 12.2 & 21.1 & 31.5 & 35.2 \\
\hline HA-B2.5 & 150 & 52.6 & 0.2 & 0.3 & $>3600$ & 8.2 & 48.3 & 17.4 & 26.1 \\
\hline FA-B & - & - & 100.0 & 100.0 & 10 & 15.1 & 32.6 & 32.6 & 19.7 \\
\hline FA-C & 0 & 0.0 & 100.0 & 100.0 & 7 & 26.9 & 35.8 & 26.9 & 10.4 \\
\hline FA-B1 & 60 & 15.6 & 68.7 & 84.4 & 30 & 18.4 & 35.5 & 30.3 & 15.8 \\
\hline FA-B1.5 & 90 & 29.3 & 39.9 & 70.5 & 41 & 18.3 & 38.1 & 28.2 & 15.4 \\
\hline
\end{tabular}

${ }^{a}$ Water drop penetration time (seconds; samples sieved at between $0.1-0.05 \mathrm{~mm}$ ).

HA, humic acid; FA, fulvic acid; C, control (unburnt); B, extracted from the post-fire soil area; B1-B2.5, laboratory-burned. 

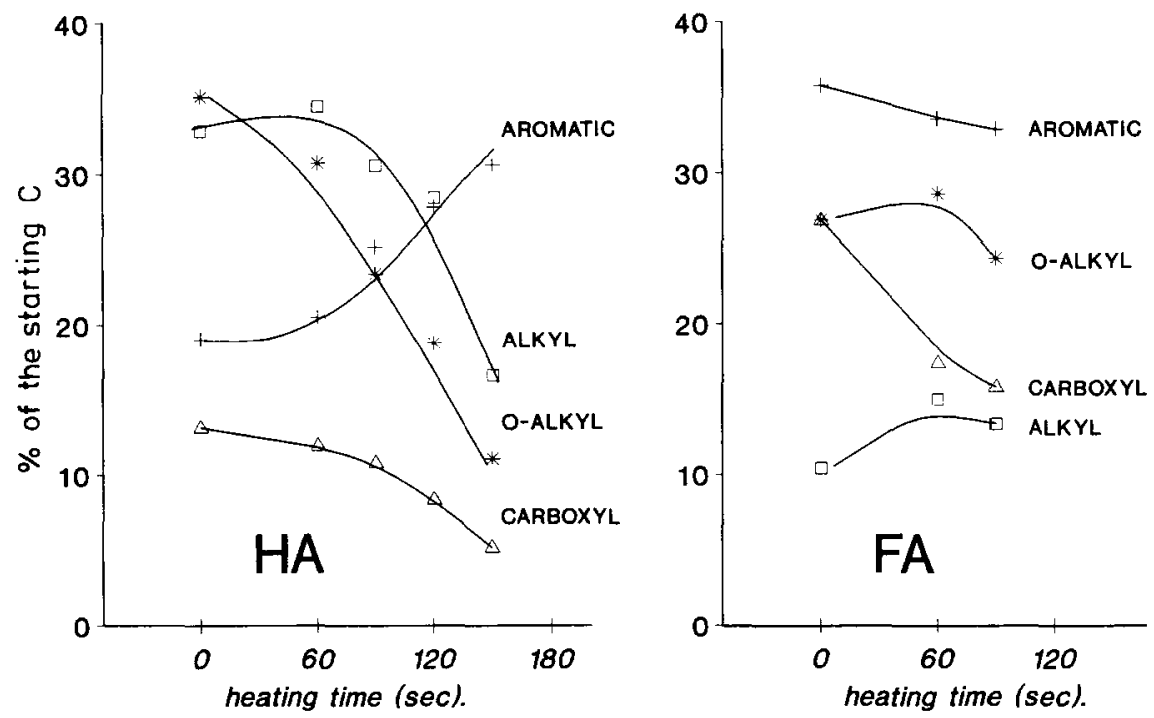

Fig. 2. Depletion of the different structural units of humic substances as results of heating humic acids (HA) or fulvic acids (FA) up to $350^{\circ} \mathrm{C}$ for $60-150 \mathrm{~s}$.

ppm. A strong decarboxylation was observed, whereas a certain increase in the H-bonded aromatic carbons occurred. The most advanced heating phases (HA-B2-HA-B2.5) were characterized by preferential losses of alkyl structures and moderate destruction of some O-alkyl material of an ill-defined carbohydrate spectral pattern.

Different tendencies were observed in the case of the FA. In addition to some unsubstituted aromatic material, new aliphatic structures can be formed in the early heating phases, a process that could be interpreted from typical reactions occurring during the formation of melanoidins or caramellike polymers [17-21]. Decarboxylation was intense at this step [22], whereas the aliphatic material and some unsubstituted aromatic structures were preferentially destroyed in the phase FA-B1-FA-B1.5.

Figure 4 shows the comparison between the unburnt HA or FA and those subjected to heating in natural or laboratory conditions. Such difference spectra were obtained from equal-area scaled spectra, with no factor multiplication, thus the positive areas show only the material that predominates in the control sample when compared with that subjected to heating, and vice-versa. The relative increase in aromaticity and the concomitant loss of aliphatic material in the HA conform to the typical response to heating of geopolymers [23], whereas in the FA intense loss of oxygencontaining functional groups occurred, and the residual material was enriched in their alkyl skeletal structures. 

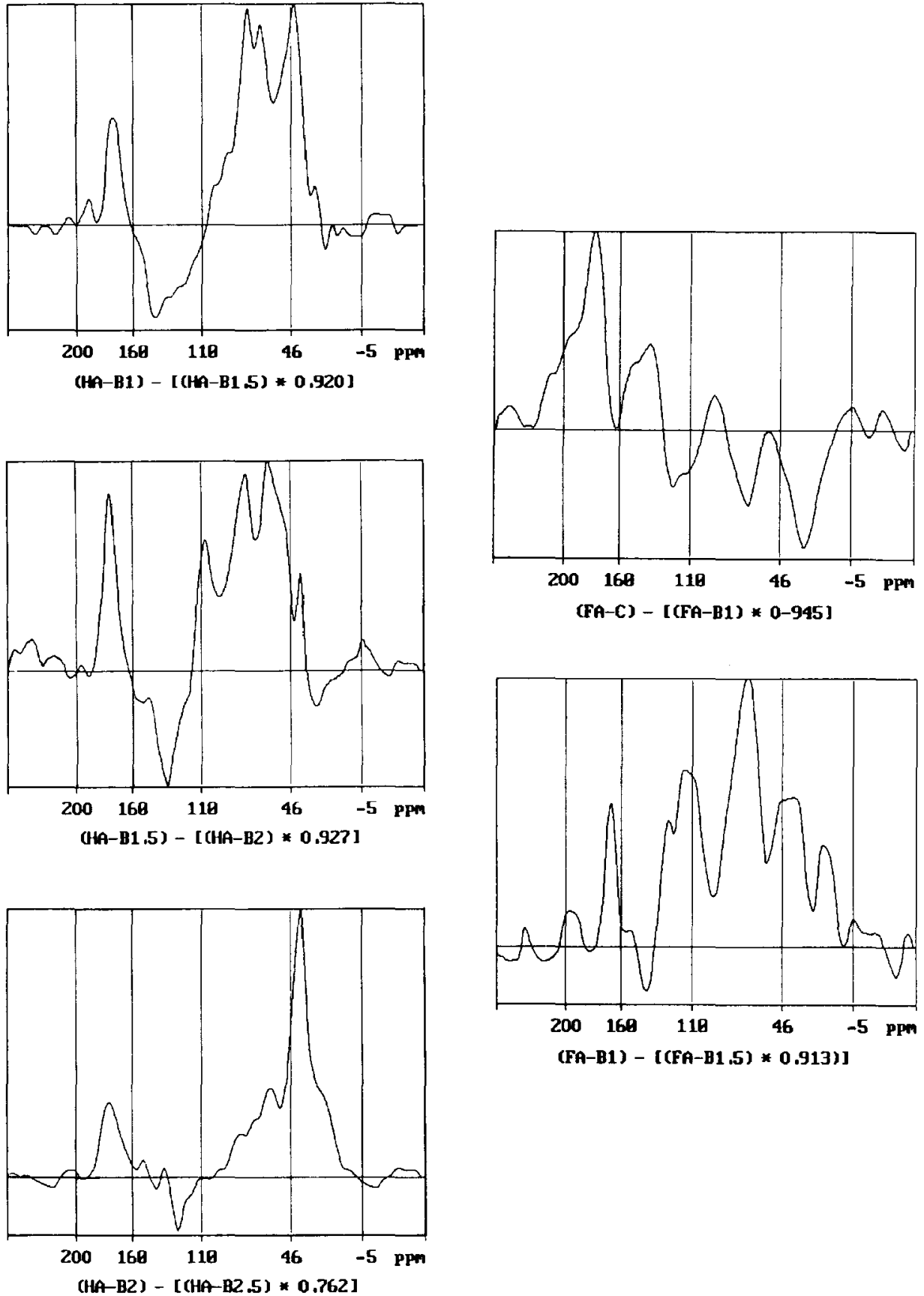

Fig. 3. Difference ${ }^{13} \mathrm{C}$-NMR spectra from heated humic acids (HA) or heated fulvic acids (FA) in which the spectra of the samples in the most advanced stages were scaled in terms of the corresponding losses of $\mathrm{C}$. 

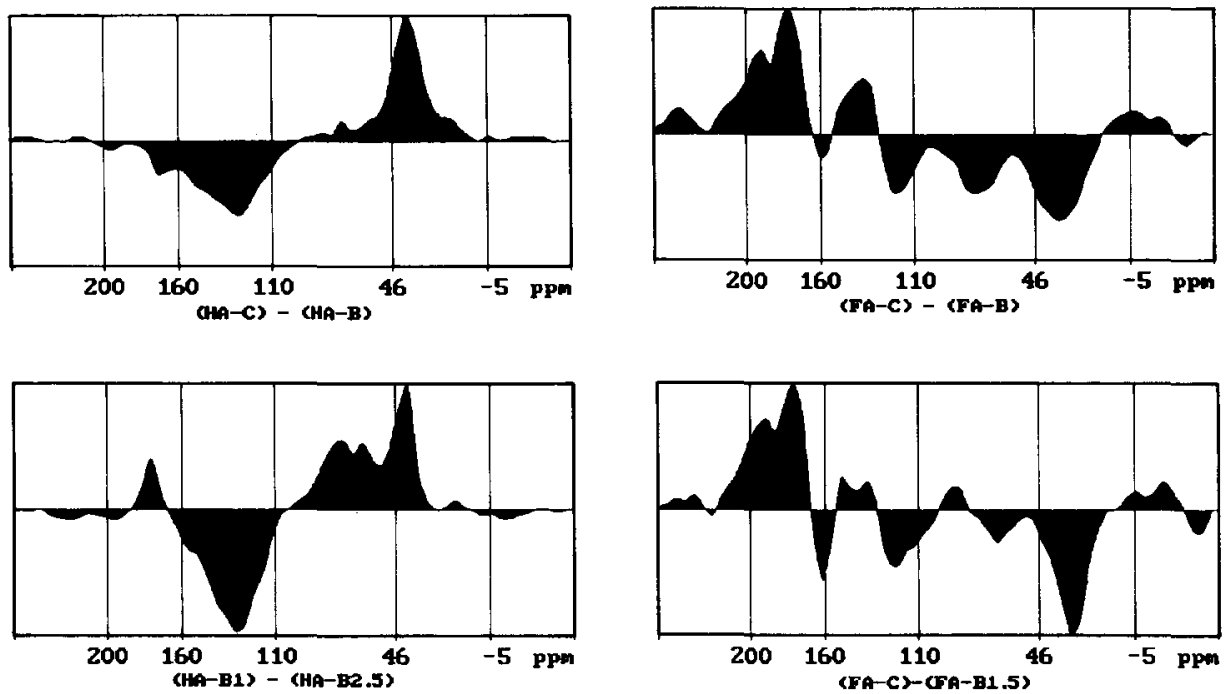

Fig. 4. Difference ${ }^{13}$ C-NMR spectra obtained from humic acids (HA) and fulvic acids (FA) from the control soil sample $(\mathrm{C})$ and the corresponding substances from the post-fire soil area (B), and from laboratory-heated humic samples (B2.5, B1.5).

The IR spectroscopy revealed additional details on the effects of heating. In Fig. 5 the raw spectra are compared with the resolution-enhanced IR spectra. After resolution enhancement, the HA-C spectrum displayed a pattern that resembled at first sight that of a lignin preparation: in addition to the aromatic ring vibrations at $1600 \mathrm{~cm}^{-1}$ and $1510 \mathrm{~cm}^{-1}$ there was a series of diagnostic peaks at 1450,1400,1365, 1325, 1265, 1220 and $1030 \mathrm{~cm}^{-1}$ [24]. The peaks at $1660 \mathrm{~cm}^{-1}$ and $1540 \mathrm{~cm}^{-1}$ corresponded to amide bands, and the carboxyl groups can be mainly responsible for the bands at around 1720 $\mathrm{cm}^{-1}, \sim 1400 \mathrm{~cm}^{-1}$ and at $770 \mathrm{~cm}^{-1}$ (carboxyl rocking). The $\mathrm{C}-\mathrm{O}$ vibration at $1770 \mathrm{~cm}^{-1}$ may be due to O-containing heterocyclic rings as cyclic anhydrides, which can be formed by heat treatment [25].

After laboratory heating (HA-B2.5) the above lignin pattern disappeared, and as did the amide bands. The IR pattern may be better interpretated by comparison with those of coals [26,27]. The relatively intense peaks at 1600 $\mathrm{cm}^{-1}$ and $1510 \mathrm{~cm}^{-1}$ and at $1450 \mathrm{~cm}^{-1}$ and $1365 \mathrm{~cm}^{-1}$, may correspond to aromatic and alkyl vibrations, respectively [13] whereas new maxima at between $900-700 \mathrm{~cm}^{-1}$ may be due to substitutions in polycyclic structures characteristic of carbonized materials.

Similar evolution occurred in the FA, where the intensity of the bands due to oxygen-containing functional groups $\left(1720 \mathrm{~cm}^{-1}, 1395 \mathrm{~cm}^{-1}, 1210 \mathrm{~cm}^{-1}\right.$ and $770 \mathrm{~cm}^{-1}$ ) decreased greatly. The major peaks corresponded to 

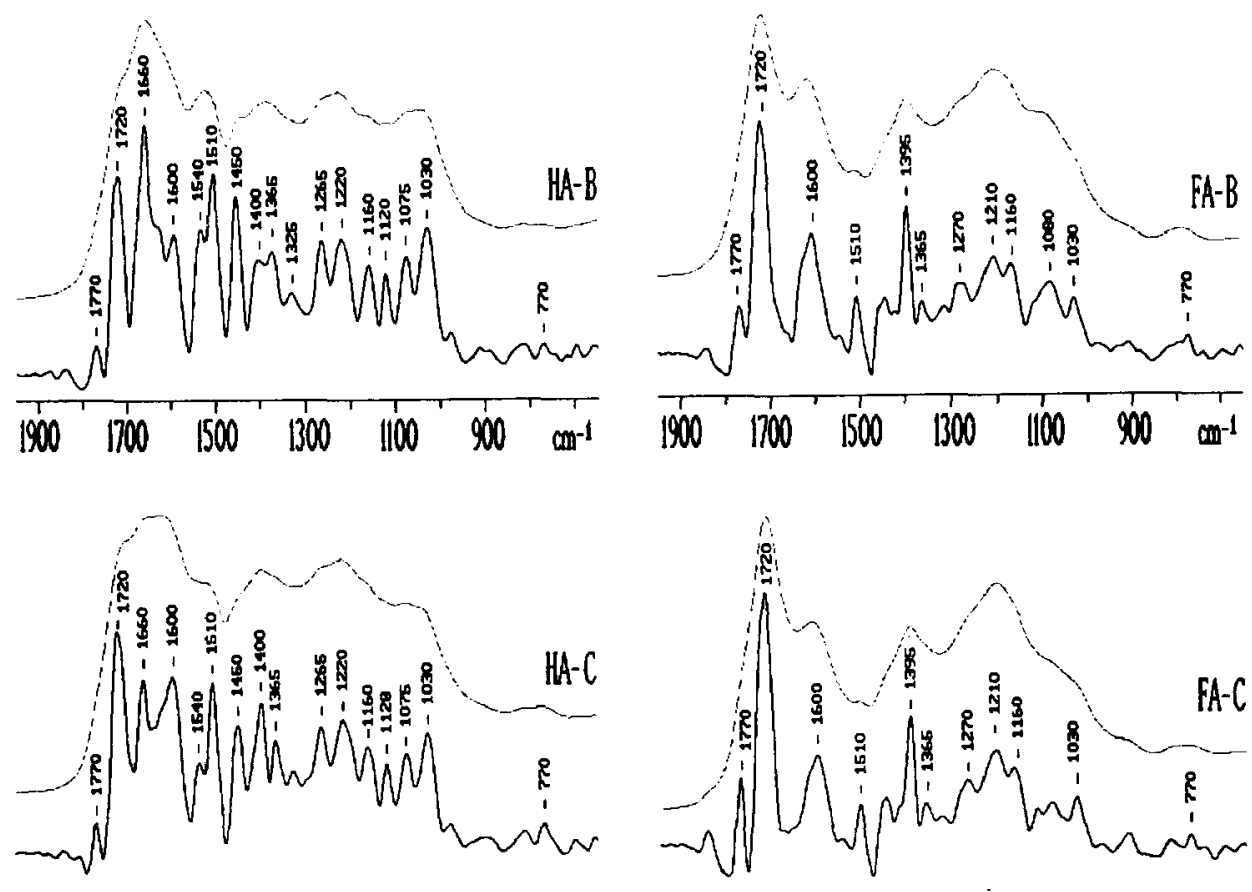

$1900100015001300 \quad 1100 \quad 000^{\circ} \mathrm{cm}^{-1}$
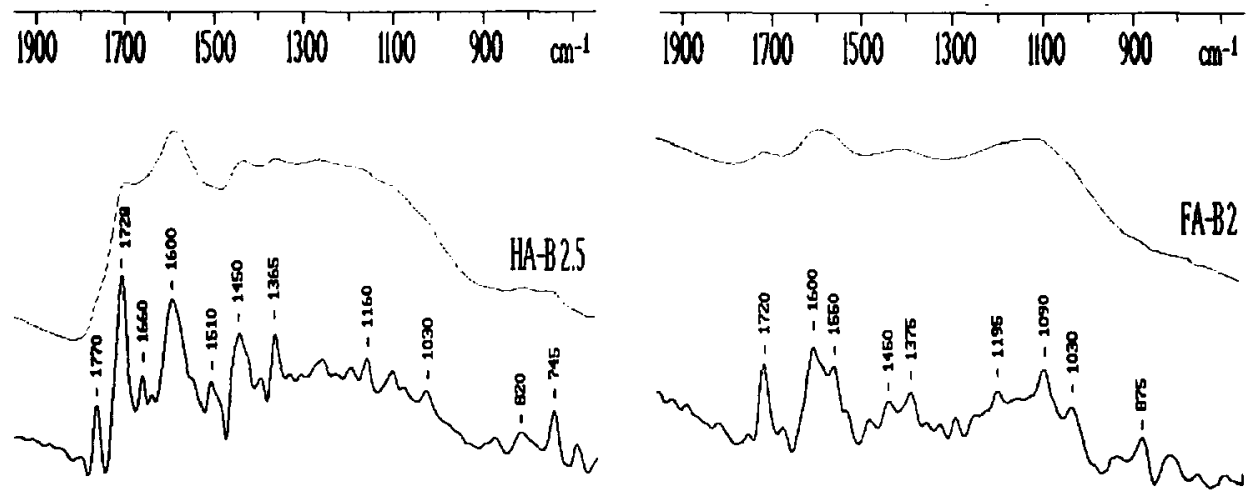

$19001700 \quad 1500 \quad 1300 \quad 1100 \quad 900 \quad 0^{1}$

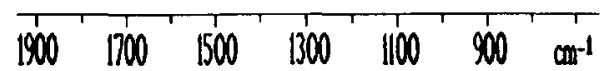

Fig. 5. Resolution-enhanced infrared spectra (continuous line) of humic acids (HA) and fulvic acids (FA) extracted from the control soil sample, (C), the post-fire soil sample (B), or subjected to laboratory heating (B2, B2.5).

aromatic and alkyl bending bands (at between $1550-1350 \mathrm{~cm}^{-1}$ ), but some alcoholic $\mathrm{OH}$ groups in carbohydrate-derived structures were suggested from the $1100-100 \mathrm{~cm}^{-1}$ region.

As expected, the changes were not noticeable when comparing the HA or FA from the control soil sample with those from the post-fire site, the latter corresponding only to the humic portion that remains soluble into alkali, 
which will necessarily represent content or types of oxygen-containing functional groups similar to that of the unburnt humic substances.

\section{CONCLUSIONS}

The results obtained suggested processes of selective degradation and the simultaneous rearrangement of the most stable humic structures. After moderate heating (up to $90 \mathrm{~s}$ at $350^{\circ} \mathrm{C}$ ), the $\mathrm{HA}$ and FA underwent dehydration and condensations in their O-alkyl structures with the concomitant increase in the proportion of aromatic components. The peaks due to $\mathrm{C}=\mathrm{O}$ groups in the HA remained intense during this phase probably due to oxidative processes compensating for the tendency to decarboxylation. These transformations conform to the concept that heat treatment at low temperatures may simulate several features of the humification process $[28,11]$. In some cases, charred lignocellulosic materials have been considered as a possible source of soil humus $[29,30]$.

After subsequent heating, the depletion of aliphatic and carboxyl groups predominated and the characteristic biopolymer patterns arising from the carbohydrate and lignin-like moieties were progressively smoothed from the NMR and IR spectral profiles.

The edaphic consequence of such phenomena would be the accumulation in soil of stable condensed substances of reduced colloidal properties. This tendency to the formation of insoluble humins is evident from the first heating phases (Table 1) and may be explained at first sight by the generalized loss of oxygen-containing functional groups. Parenthetically, it may be noted than the quantitative values of carboxyl C's lie between the variability for HA's from different origins that are perfectly soluble in alkali. The contribution of additional processes may be hypothesized, such as condensation of the polymer structure (predominance of low-reactivity oxygen-containing groups) as well as severe changes in the surface properties (peripheral arrangement of unsubstituted alkyl or aromatic structures). In fact, a very striking characteristic of the humic substances subjected to heating was their intense water-repellency. The values indicated in Table 1 correspond to the water drop penetration time [6]; such values show that thermal treatment turns the humic substances into hydrophobic polymers. This phenomenon is particularly relevant in the soil under study, which presented decreased wettability in the post-fire site [11], that could not be explained in terms of the accumulation of substances soluble in organic solvents [31].

The above processes of accumulation in soil of 'hydrophobic humin' might have great importance in Mediterranean areas, where the effects of fires are frequently recognized in terms of changes in the structure and hydrophysical properties of soils. 
The first author wishes to acknowledge the technical assistance of Mrs Maria Nieves Garcia-Acha and Mrs Maria Dolores Ramírez. This study has been supported in part by the Spanish CICYT (grant NAT89-0936).

\section{REFERENCES}

1 P.J. Viro, Effects of forest fire on soil, in T.T. Kozlowski and C.E. Ahlgreen (Eds), Fire and Ecosystems, Academic Press, New York, 1974, pp. 8-45.

2 L.F. de Bano, P.H. Dunn and D.A. Conrad, Fire's effect on physical and chemical properties of chaparral soils, in Proc. Symp. Environmental Consequences of Fire and Fuel Management in Mediterranean Ecosystems, USDA, Forest Service, CA, 1977, pp. 65-74.

3 G. Giovannini and S. Lucchesi, Effect of fire on hydrophobic and cementing substances of soil aggregates. Soil Sci., 136 (1984) 231-236.

4 G. Almendros, A. Polo, J. Ibáñez and M.C. Lobo, Contribución al estudio de la influencia de los incendios forestales en las características de la materia orgánica del suelo. II: Transformaciones del humus por ignición en condiciones controladas de laboratorio. Rev. Ecol. Biol. Sol, 21 (1984) 145-160.

5 J.A. Vega, La investigación sobre incendios forestales en España. Revisión bibliográfica. Bases Ecológicas para la Gestión Ambiental. Diputación de Barcelona, España, 1986, pp. 17-24.

6 S.M. Savage, J. Osborn, J. Letey and C. Heaton, Substances contributing to fire-induced water repellency in soils. Soil Sci. Soc. Am. Proc., 36 (1972) 674-678.

7 D.G. Scholl, Soil wettability and fire in Arizona chaparral. Soil Sci. Soc. Am. Proc., 39 (1975) 356-361.

8 L.F. de Bano, S.M. Savage and D.A. Hamilton, The transfer of heat and hydrophobic substances during burning. Soil Sci. Soc. Am. J., 40 (1976) 779-782.

9 G. Almendros, F. Martín and F.J. González-Vila, Effects of fire on humic and lipid fractions in a Dystric Xerochrept in Spain. Geoderma, 42 (1988) 115-127.

10 M.A. Wilson, NMR Techniques and Applications in Geochemistry and Soil Chemistry, Pergamon, Oxford, 1987.

11 G. Almendros, F.J. González-Vila and F. Martín, Fire-induced transformation of soil organic matter from an oak forest. An experimental approach to the effects of fire on humic substances. Soil Sci., 149 (1990) 158-168.

12 R. Fründ and H.-D. Lüdemann, The quantitative analysis of solution and CPMAS-C-13 NMR spectra of humic material. Sci. Total Environ., 81/82 (1989) 157-168.

13 S.-H. Wang and P.R. Griffiths, Resolution enhancement of diffuse reflectance i.r. spectra of coals by Fourier self-deconvolution. 1. C-H stretching and bending modes. Fuel, 64 (1985) 229-236.

14 W.-J. Yang, P.R. Griffiths, D.M. Byler and H. Susi, Protein conformation by infrared spectroscopy: resolution enhancement by Fourier self-deconvolution. Appl. Spectrosc., 39 (1985) 282-287.

15 W. Gerasimowicz, D. Byler and H. Susi, Resolution-enhanced FT-IR of soils constituents: humic acid. Appl. Spectrosc., 40 (1986) 504-507.

16 A. Rosenfeld and A. Kak. Digital Image Processing, Vol. 1., Academic Press, Amsterdam, 2nd edn., 1982. 
17 J.E. Hodge, Chemistry of browning reactions in model systems. Agric. Food Chem., 1 (1953) 928-943.

18 J.I. Hedges, The formation and clay reactions of melanoidins. Geochim. Cosmochim. Acta, 42 (1978) 69-76.

19 M.S Feather and J.F. Harris, Dehydration reactions of carbohydrates. Adv. Carbohydr. Chem. Biochem., 28 (1973) 161-224.

20 L.M. Benzing-Purdie and J.A. Ripmeester, Melanoidins and soil organic matter: evidence of strong similarities revealed by ${ }^{13} \mathrm{C}$ CP-MAS NMR. Soil Sci. Soc. Am. J., 47 (1983) 56-61.

21 G. Almendros, J. Sanz and I. Sobrados, Characterization of synthetic carbohydratederived humic-like polymers. Sci. Total Environ., 81/82 (1989) 91-98.

22 H. Kodama and M. Schnitzer, Kinetics and mechanism of the thermal decomposition of fulvic acid. Soil Sci., 109 (1970) 265-271.

23 L.W. Dennis, G.E. Maciel, P.G. Hatcher and B.R.T. Simoneit, ${ }^{13} \mathrm{C}$ Nuclear magnetic resonance studies of kerogen from Cretaceous black shales thermally altered by basaltic intrusions and laboratory simulations. Geochim. Cosmochim. Acta, 46 (1982) 901-907.

24 D. Fengel and G. Wegener, Wood-Chemistry, Ultrastructure, Reactions, Walter de Gruyter, Berlin, 1984.

25 J.R. Wright and M. Schnitzer, An estimate of the aromaticity of the organic matter of a podzol soil. Nature, 4777 (1961) 703-704.

26 H.W. van der Marel and H. Beutelspacher, Atlas of Infrared Spectroscopy of Clay Minerals and their Admixtures, Elsevier, Amsterdam, 1976.

27 B.E. Durand, Kerogen. Insoluble Organic Matter from Sedimentary Rocks. Editions Technip, Paris, 1980.

28 A. Gutsze, M. Pacek and H. Dziadowiec, Electron paramagnetic resonance in humic substances. J. Soil Sci., 40 (1989) 879-889.

29 K. Kumada, Carbonaceous materials as possible source of soil humus. Soil Sci. Plant Nutr., 29 (1983) 383-386.

30 H. Shindo, Y. Matsui and T. Higashi, A possible source of humic acids in volcanic ash soils in Japan-charred residue of Miscanthus sinensis. Soil Sci., 141 (1986) 84-87.

31 S.M. Savage, Mechanism of fire-induced water repellency in soil. Soil Sci. Soc. Am. Proc., 38 (1974) 652-657. 